\title{
De E. Husserl a J. L. Marion: donación y límites de la fenomenología
}

Hernán G. Inverso*

\section{Resumen}

En este trabajo nos referiremos a la recepción francesa operada en Derrida y Marion respecto del tratamiento heideggeriano acerca de los alcances y límites de la fenomenología, a partir del problema de la posibilidad del don y su relación con la reducción como estrategia propiamente fenomenológica. Inicialmente, presentaremos un breve relevamiento de los elementos de la propuesta de Heidegger que despuntaron las perspectivas posteriores, constituidas por las posiciones de J. Derrida en torno de la imposibilidad del don, donde prestaremos especial atención a las críticas al «anonadamiento» husserliano y la «esperanza» heideggeriana como mecanismo para redefinir la lógica del don, y de J. L. Marion, quien objeta la postura deconstruccionista proponiendo un mecanismo de reducción del don a la donación. Esto nos permitirá sentar las bases para una evaluación global de este recorrido y las reacciones que ha suscitado en relación con las proyecciones actuales de la disciplina.

Cursó sus estudios de Licenciatura en Filosofía en la Facultad de Filosofía y Letras de la Universidad de Buenos Aires, es becario de esta Universidad e integra proyectos de investigación en la Universidad de Buenos Aires, la Universidad Nacional de San Martín y la Comisión Nacional de Investigaciones Científicas y Técnicas (CONICET). Ha participado de numerosas instancias académicas a través de la presentación de ponencias y ha publicado artículos sobre fenomenología y sobre sus conexiones con tópicos desarrollados en la antigüedad. Sus estudios doctorales abarcan aspectos de la fenomenología francesa contemporánea. Contacto: hernaninverso@gmail.com. 


\title{
Palabras clave
}

Fenomenología, donación, reducción, deconstrucción, teología.

\section{From E. Husserl to J. L. Marion: Donation and Limits of Phenomenology}

\begin{abstract}
This article studies the French reception done by Derrida and Marion in relation to Heidegger's treatment of the extent and limits of phenomenology. This perspective begins with the problem of the possibility of the gift and its relationship to reduction as a phenomenological strategy. First, we present a brief exposition of the elements within the heideggerian proposal that emerged in later views. We study the thesis of J. Derrida about the impossibility of the gift, paying special attention to his criticism about husserlian «annihilation» and heideggerian «hope» as a mechanism to redefine the logic of the gift, and the thesis of J. L. Marion, who rejects the deconstructionist position and proposes a reduction mechanism from the gift to donation. This allows us to achieve a comprehensive evaluation of this theoretical route and its reactions in relation to current projections of the discipline.
\end{abstract}

\section{Keywords}

Phaenomenology, givenness, reduction, deconstruction, theology.

\section{Introducción}

Nuestra época asiste a una sostenida discusión sobre la vigencia y límites de la fenomenología, que pone en primer plano la cuestión de la identidad y los núcleos de permanencia de este enfoque que, desde sus inicios, atravesó modificaciones sustantivas. Basta pensar en el 
desarrollo que adoptó en manos de Husserl y las derivas y metamorfosis que advinieron con Heidegger. En buena medida en estas tensiones iniciales está preanunciada la discusión posterior que nos interesa revelar en este trabajo, especialmente a partir de la noción de es gibt y el despliegue del problema de la donación, que condujo a rever la relación entre fenomenología y teología y a explorar la plausibilidad de una fenomenología de lo inaparente. Este planteo despliega una serie de conexiones entre nociones nucleares: el haber, que se muestra como es gibt -literalmente «se da»-, establece un vínculo entre ser y donación, noción que traería aparejada su propia lógica compuesta de la trilogía de donador-don-donatario, por definición anclada en las relaciones mundanas. Pero a la vez, el don y su relación con la gratuidad traen aparejada la noción de presente, en tanto cosa que se trae a la presencia frente a otro para entregarla, y con ella toma primacía la dimensión de la temporalidad. La tensión entre ser, tiempo y entes queda en primer plano y se transforma unas veces en la base de una nueva forma de fenomenología y otras en su acta de defunción.

En este recorrido nos referiremos a la recepción francesa operada en Derrida y Marion respecto de los tópicos heideggerianos acerca de los alcances y límites de la fenomenología. Partiremos del problema de la posibilidad del don y su relación con la reducción como estrategia propiamente fenomenológica. En primer lugar, presentaremos un breve revelamiento de los elementos de la propuesta de Heidegger que despuntaron las perspectivas posteriores (punto 1), constituidas por las posiciones de J. Derrida en torno de la imposibilidad del don y prestaremos especial atención a las críticas al «anonadamiento» husserliano y la «esperanza» heideggeriana como mecanismo para redefinir la lógica del don (punto 2). A continuación, examinaremos los planteos de J. L. Marion, que objeta la postura deconstruccionista con su propuesta de un mecanismo de reducción del don a la donación (punto 3). Esto nos permitirá sentar las bases para una evaluación global de este recorrido y las reacciones que ha suscitado en relación con las proyecciones actuales de la disciplina (punto 4). 


\section{Desplazamiento de la reducción y darse del ser}

El decurso de la fenomenología resulta una progresiva creación de modelos de epoché que se distancian de los casos estudiados por Husserl en su primera época. En efecto, la filosofía husserliana adoptó como fundamento la reducción fenomenológica en la cual el mundo es suspendido, de modo que la atención se vuelve hacia los correlatos noético-noemáticos de la conciencia. Frente a esto, si se presta atención a la última época del pensamiento husserliano, se constata que la epoché no implica, entonces, una pérdida, ni hay residuo fenomenológico, como si supusiera una carencia, sino que el correlato de la subjetividad trascendental es el mundo mismo con todo su verdadero ser. Tras la epoché se introduce un cambio de actitud que amplía en lugar de reducir el campo de la experiencia. Lo que queda por el camino en esta modificación es el dispositivo de prejuicios que entorpecen el acceso al mundo. Sólo de este modo la fenomenología trascendental puede ser una efectiva ontología. La constitución es el proceso que permite que lo constituido aparezca y se muestre tal cual es, y en él yo y no yo son momentos inseparables e irreductibles.

Así, no basta con el plano de la subjetividad, sino que el mundo está implicado, sin que ello suponga un nuevo dualismo sino la imposibilidad de pensarlos como instancias separadas. Por el contrario, se integran con el elemento intersubjetivo que lleva a la fórmula de la nota del final del n. ${ }^{\circ} 62$ de Ideas II: «Así pues, yo, nosotros y el mundo nos pertenecemos mutuamente» ${ }^{1}$ (Also ich, wir, die Welt gehören zusammen). De este modo surge el perfil de una epoché que no es suspensión -o sólo suspensión- del mundo, sino que resulta un elemento que permite aproximarse al mundo sin que pierda nada de su ser u objetividad, como se afirma en el n. ${ }^{\circ} 41$ de La crisis de las ciencias europeas ${ }^{2}$.

1 Edmund Husserl, Ideas II. Pertaining to a Pure Phenomenology and to a Phenomenological Philosophy, trad. R. Rojcewicz (New York: Springer, 1990), 288.

2 Cf. Edmund Husserl, La crisis de las ciencias europeas y la fenomenología trascendental, trad. y nota editorial de Jacobo Muñoz y Salvador Mas (Barcelona: Crítica, 1991). 
En este desplazamiento se asentó la posición de Heidegger para señalar la necesidad de colocar el punto de partida del pensar en la comprensión del mundo cotidiano. Así, el poner entre paréntesis husserliano contrasta con el comprender «el ser en el mundo» de la vertiente existencial. Este contraste impulsó la toma de posición en las líneas posteriores que adhirieron a la fenomenología llevándolas a redefinir la noción de reducción. En efecto, el análisis de los existenciarios del Dasein se transformó a partir de la Kehre en una impugnación de la metafísica de la presencia. Por esta vía se dictó la sospecha respecto de los elementos de subjetividad que operaban tras la noción de Dasein y, consecuentemente, emergió la necesidad de avanzar hacia una tematización del ser que no se desviara a través de esas sendas peligrosas.

Esta tarea concita la atención del segundo Heidegger, como se ve claramente en los planteos de Tiempo y ser, donde se traspone el clima de Ser y tiempo, en el cual la pregunta por el ser llevaba al Dasein, para desplegar el programa de pensar el ser sin el ente. Esta tarea no acometida por la metafísica siempre había sido supuesta pero no tematizada. En este plexo de ideas cobra relevancia la temática de la donación que será de fundamental importancia en las proyecciones de los exégetas y continuadores del pensamiento heideggeriano. Heidegger opera con la expresión es gibt a través de su obra en varios contextos ${ }^{3}$. Si apelamos a las coordenadas de Ser y tiempo, el tiempo da el ser, dado que este solo puede ser comprendido en la finitud del Dasein. En este sentido, en Los problemas básicos de la fenomenología, de 1927, sostiene Heidegger que

Tal vez no hay otro ser más allá del que ha sido enumerado, pero tal vez, como en el idioma alemán para "hay" (es gibt) aún algo más es dado. Aún más. Al fin algo es dado lo cual debe ser dado si vamos a hacer a los seres accesibles a nosotros como seres y conducirnos a nosotros mismos

3 Para un estudio detallado de los sentidos de la expresión es gibt en la obra de Heidegger, véase R. Horner, Rethinking God as Gift. Marion, Derrida and the Limits of Phenomenology (New York: Fordham University Press, 2001), 32 ss., a quien seguimos en la caracterización general. 
hacia ellos, algo que, para estar seguros, no es sino lo que debe ser dado si vamos a experimentar y entender cualquier ser $^{4}$.

Si avanzamos hasta la Carta sobre el humanismo, de 1946, encontramos que se señala que el Es de Es gibt es el ser que "se da» a sí mismo bajo la forma de la presencia. Esta formulación prepara el camino para el planteo tardío de Tiempo y ser, de 1962, donde sostiene que la noción de ser no se aplica a ser y tiempo, dado que estos hacen ser a los entes y los entes son los únicos a los que se aplica la existencia. A partir del análisis de las expresiones Es gibt Sein y Es gibt Zeit, se sanciona que tiempo y ser no son, sino que les corresponde el darse, donde este Es (se) resulta un equivalente del Ereignis, el evento, acontecimiento o acontecimiento apropiador-aludiendo a su relación con eigen, "propio»-, que no es una ocurrencia sino «lo que hace posibles las ocurrencias» ${ }^{5}$ en tanto condición de posibilidad de ser y tiempo.

En efecto, para evitar recaer en las coordenadas ónticas, Heidegger plantea en El principio de identidad, en 1957, la necesidad de un «salto» que trasponga la representación, es decir, la relación sujeto-objeto, que quedó sedimentada a lo largo de la historia de la metafísica de Occidente. Este salto que lleva más allá de la presencia y del ser mismo alcanza el plano de la copertenencia de ser y pensar, hasta la dimensión del Ereignis. Este papel central, que coloca al Ereignis como noción nuclear no solo del planteo del último Heidegger sino de su obra en general, está planteado por $\mathrm{M}$. Berciano, que sostiene:

la reflexión al comienzo del pensar heideggeriano sobre el flujo histórico de las vivencias, sus reflexiones posteriores sobre el ser y el tiempo, y su ulterior concepción de la verdad como acaecer histórico, son un constranscripción inglesa de Albert Hofstader, The Basic Problems of Phenomenology. Studies in Phenomenology and Existential Philosophy (Indiana: Indiana University Press, 1927), 14-5.

5 Martin Heidegger, «Tiempo y ser», trad. M. Garrido y Félix Duque, en Tiempo y ser (Madrid: Tecnos, 2000), 19 . 
tante camino hacia el ser como evento, primero, y hacia el evento como evolución definitiva, que da ser y tiempo ${ }^{6}$.

Una cuestión adicional radica en analizar la contuinuidad y cohesión del planteo de Heidegger, que se apoya en la tematización de la historia de la metafísica en términos de caída aliada al olvido del ser hasta arribar a «la época que es época» y su plasmación en el Gestell en tanto preludio del Ereignis ${ }^{7}$. Este planteo conllevó procesos de ruptura y discontinuidad en el seno de la fenomenología posterior, como veremos en el punto 4, tras avanzar en la revisión de dos líneas inspiradas explícitamente en Heidegger que han reflexionado sobre las potencialidades y límites de este enfoque.

\section{La imposibilidad del don}

La recepción de este planteo en la discusión posterior ha sido amplia y marcó una serie de posicionamientos teóricos que enfrentaron a pensadores como Derrida y Marion en la reflexión sobre los límites de la fenomenología. Detengámonos en la propuesta derridiana, que se propone como una lectura consecuente con los presupuestos heideggerianos, pero que muestra que precisamente si se es fiel a dichos presupuestos la donación se revela imposible. En efecto, dirá Derrida en el primer capítulo de Dar el tiempo, «El tiempo del rey», que «las condiciones de posibilidad del don designan las condiciones de imposibilidad del don $»^{8}$.

La categoría de olvido, que Heidegger enfatizó en Tiempo y ser como dimensión básica que afecta al ser, sirve en Derrida para su propia propuesta al asociar la lógica del don precisamente con el requisito de olvido. Derrida sostiene que para que haya don, algo debe ocurrir en un instante que no pertenezca a la economía del tiempo y para ello apela al modo en que Heidegger afirma que tiempo y ser no existen,

Cf. M. Berciano, «Ereignis. La clave del pensamiento de Heidegger», Themata 28 (2002): 69. Martin Heidegger, Identidad y diferencia, trad. Helena Cortés y Arturo Leyte (Barcelona: Anthropos, 1990), 77 y 79.

8 J. Derrida, Dar el tiempo, trad. Cristina de Peretti (Buenos Aires: Paidós, 1991), 21. 
dado que no son entes, sino que pertenecen al ámbito del Es gibt, «se da». Ahora bien, puntualiza Derrida, el olvido del ser es correlativo de la irrupción del sujeto, mecanismo que instaura el ámbito de lo calculable y, por ende, la irremisible relación de intercambio entre donadordon-donatario que produce una triple paradoja. Con esto muestra el modo en que cada uno de los constituyentes provoca la aniquilación de la gratuidad asociada intrínsecamente con la noción de don:

El don debe, también por parte del «sujeto» donador, no sólo no ser correspondido sino que ni siquiera debe ser (res)guardado en la memoria, retenido como símbolo de un sacrificio, como simbólica en general. Pues el símbolo obliga inmediatamente a la restitución (Car le symbole engage immédiatement dans la restitution). A decir verdad, el don ni siquiera debe aparecer o significar, consciente o inconscientemente, en calidad de don ante los donatarios, ya sean estos sujetos individuales o colectivos. En cuanto el don aparezca como don, como tal, como lo que es, en su fenómeno, su sentido y su esencia, estará implicado en una estructura simbólica, sacrificial o económica que anulará el don en el círculo ritual de la deuda (il serait engagé dans une structure symbolique, sacrificielle ou économique qui annu- lerait le don dans le cercle rituel de la dette). La mera intención de dar, en la medida en que comporta el sentido intencional del don, basta para dar por descontada la reciprocidad. La mera conciencia del don se devuelve a sí misma de inmediato la imagen gratificante de la bondad o de la generosidad, del ser-donante que, sabiéndose tal, se reconoce circular, especularmente, en una especie de autorreconocimiento, de aprobación de sí mismo y de gratitud narcisista (dans une sorte d'auto-reconnaissance, d'approbation de soi-même et de gratitude narcissique) ${ }^{9}$.

En síntesis, de esto se deduce lo siguiente: basta con que el donador perciba para que surja una autogratificación que opera como devolución; basta que el don se haga "presente» para que active la lógica de los entes; basta que el donatario perciba para que produzca un contra-don, aunque sea simbólico. El don supone un aspecto aneconómico ${ }^{10}$. Lo aneconómico del don, por su parte,

10 «¿Pero el don, si lo hay, acaso no es también aquello mismo que interrumpe la economía? (Mais le don, s'il y en a, n'est-ce pas aussi cela même qui interrompt l'économie) ¿̇Aquello mismo que, al suprimir el cálculo económico, ya no da lugar al intercambio? (...) Si hay don, lo dado del don (lo que se da, lo que es dado, el don como cosa dada o como acto de donación) no debe volver al donante (ne doit pas revenir au donnant) (no digamos aun al sujeto, al donador o a la donadora). No debe circular, no debe intercambiarse, en cualquier caso no debe agotarse, como don, en el proceso del intercambio (Il ne doit pas circuler, il ne doit pas s'échanger, il ne doit en tout cas être épuisé, en tant que don, par le procès de l'échange) (...). Puede ser que sea en este sentido en el que el don es lo imposible (le don est l'impossible)». Ibíd., 32. 
se opone a la lógica del intercambio, de modo tal que en el ámbito de la reciprocidad no existe sino un simulacro económico del don. La triple paradoja sanciona la imposibilidad del don. Para mostrar dicha imposibilidad, en el final del primer capítulo y la totalidad del segundo de Dar el tiempo Derrida procede al análisis del concepto de don instalado en la tradición por M. Mauss en su Ensayo sobre el don, de 1925. Mauss fue responsable de la introducción de una línea durkheimiana en la etnología francesa, tomando como base la antropología estructuralista de C. Levi Strauss y M. Godelier y, por supuesto, en el Mouvement Anti-Utilitariste en Sciences Sociales (MAUSS). En su planteo instaló el don como dimensión que sostiene el tejido social a través del establecimiento de obligaciones que sustituyen el intercambio inmediato de bienes por una lógica de demora con contra-don diferido, tal como muestran los ejemplos surgidos del caso del potlatch de los pueblos originarios de América del Norte.

Con la ventaja de no reducir estas operaciones interpersonales a lo puramente mercantil, Derrida sostiene, sin embargo, que Mauss no da cuenta del don sino que su análisis se restringe a la lógica de intercambio, donde llega a entrever la dimensión de exceso respecto de lo económico, pero sin tematizarla ni llegar a comprender la operatoria de la triple paradoja ${ }^{11}$.

Las críticas a Mauss permiten internarse en la dimensión del exceso. En efecto, la estructura del segundo capítulo de Dar el tiempo, «Locura de la razón económica: un don sin presente», muestra dos ejemplos de maniobra léxica identificados por Derrida: la corrección de terminología económica en términos de don y la relación entre don y crédito. Ambas le permiten tematizar la diseminación e incineración del sentido de «don». Tras un análisis de casos que Mauss logra reducir al intercambio, la atención se desplaza a aquellos donde esto se vuelve imposible:

11 En efecto, para Derrida «A Mauss no le inquieta demasiado esa incompatibilidad entre el don y el intercambio, o el hecho de que un don intercambiado no sea más que un toma y daca, es decir, una anulación del don", Ibíd., 44. 
Su lenguaje se vuelve loco ( $s^{\prime}$ affole) en el momento en que, en el potlatch, el proceso del don se arrebata ( $s^{\prime}$ emporte lui-même) y en que-viene a decir Mauss- «no se trata siquiera de dar ni de devolver sino de destruir, a fin de no querer siquiera que parezca que desean que se les devuelva nada...». El temblor de esta incertidumbre afecta a la palabra «don» pero también a la palabra «intercambio» que Mauss asocia regularmente con la anterior ${ }^{12}$.

En los ejemplos del potlatch de revancha y destrucción, que sanciona la aniquilación de la relación entre don e intercambio, hay una diseminación sin retorno que destruye toda posibilidad de identificar un foco semántico para los lexemas asociados con don. Los casos en que el don se produce para ganar prestigio social o provocar un daño al otro son indicio de una dimensión que supera lo económico y hace necesario reconsiderar la lógica del don. A propósito de esto plantea:

El principio del antagonismo y de la rivalidad fundamenta todo. (...) En un buen número de casos, no se trata siquiera de dar ni de devolver, sino de destruir, a fin de no querer siquiera que parezca que desean que se les devuelva nada [Soy yo quien subraya, J.D.]. Se queman cajas enteras de aceite de olachen (candle-fish, pez-bujía) o de aceite de ballena, se queman las casas y miles de mantas; se rompen los más valiosos cobres, se los arroja al agua para aniquilar, para «aplastar» al rival ${ }^{13}$.

El hincapié reside, como es claro, en que esta práctica de donación excede el intercambio, como se ve igualmente en el relato de Mauss acerca del mito de Haiyas, donde el potlatch se aplica a un juego de azar atravesado por la cuestión del honor, en el cual hay partido y revancha en los que los intervinientes deciden cuestiones vitales ${ }^{14}$. La cuestión central que surge de esta situación apunta a señalar que el propio Mauss caracteriza el lexema «don» como un híbrido de gratuidad e interés. En este momento en la construcción unívoca implosiona haciendo de «don» un indecidible en términos derridianos.

Una revisión del texto, entonces, muestra el posicionamiento de Derrida frente a la noción de don en la tradición antropológica, pero es preciso enfatizar que, como hemos dicho, al mismo tiempo

Ibíd., cap. 2, nota 5 . 
se enrola, con distancia crítica, en la línea abierta por Husserl y Heidegger. En efecto, donador y donatario configurados como sujetos y don convertido en objeto se convierten en «trabas del don» ${ }^{15}$ que conllevan su inmediata y consecuente aniquilación. De un modo más básico, toda temporalización inicia la destrucción del don, de manera que el don solo es posible como restancia sin memoria, en tanto huella sin presencia plena, resistente a cualquier cognición. No hay entonces posibilidad de una fenomenología del don y de este modo el programa heideggeriano de pensar el ser sin el ente se revela como una quimera. Más aun, resulta un residuo que Derrida caracterizará como infundada «esperanza».

La relación entre estos planteos es explícita, hasta el punto de que Derrida reconoce en Posiciones el papel de Heidegger como punto de partida de su pensamiento ${ }^{16}$ y aclara que se aparta especialmente en torno de las nociones de origen y caída, que revelan aspectos que no abandonan la «metafísica de la presencia ${ }^{17}$. Desde esta perspectiva, detrás de la noción de Ereignis se sospecha una noción de verdad asociada con la captación unívoca de un origen único, contrario a los lineamientos de la huella sin origen que guía su propia búsqueda antifundacionista ${ }^{18}$.

Para esclarecer este punto es necesario prestar atención a la nota 8 del segundo capítulo de Dar el tiempo. A la manera de una estrategia de deconstrucción, que pone en el centro aquello que estaba en los márgenes, el contenido de esta nota alumbra la conexión de la dinámica del don con las posiciones fenomenológicas de Husserl, Heidegger y Marion.

15 Ibíd., 22.

16 «Mantengo, como recuerda en su pregunta, que el texto de Heidegger es para mí de una extrema importancia, que constituye una avanzada inédita, irreversible y que estamos todavía muy lejos de haber explotado todos los recursos críticos». Cf. J. Derrida, Posiciones, trad. M. Arranz (Valencia: Pre-Textos, 1977), 9-10.

17 «a veces tengo el sentimiento de que la problemática heideggeriana es la defensa más "profunda" y más "poderosa" de lo que trato de cuestionar bajo el título de pensamiento de la presencia». Ibíd., 54.

18 Sobre este punto, Cf. J. Caputo, God, the Gift, and Postmodernism (Indianapolis: Indiana University Press, 1999), 178 y R. Horner, op. cit., 42. 
En este contexto, y en diálogo con Marion, se dice que

Husserl, en efecto, totalmente deslumbrado por la donación sin límite (complètement ébloui par la donation sans limite), parece no percatarse de lo extraño de semejante desmesura y administra solamente el exceso de la misma, sin cuestionarlo (semble ne pas s'aviser de l'étrangeté d'une telle démesure, et en gère seulement l'excès, sans l'interroger) ${ }^{19}$.

Desde esta perspectiva, Husserl se deslumbra ante la donación originaria y opera con ella sin tematizarla, y con ello produce una «detención metafísica» que no la libera del «encarcelamiento de la presencia». Husserl queda con esto condenado entre los cultores del logocentrismo. Inmediatamente se menciona a Heidegger, a quien se asocia allí con la relación entre donación y llamada. En este marco, el compromiso con una metafísica de la presencia que se atribuye a Husserl opera en algún sentido también respecto de su continuador, que bosqueja los rasgos de la ontoteología tradicional. Derrida adopta este enfoque explícitamente en La différance, donde se refiere a un análisis acerca del lenguaje de Anaximandro en el que Heidegger sostiene:

La relación con el presente, que muestra su orden en la esencia misma de la presencia, es única (ist eine einzige). Permanece por excelencia incomparable a cualquier otra relación, pertenece a la unicidad del ser mismo (Sie gehört zur Einzigkeit des Seins selbst). La lengua debería, pues, para nombrar lo que se muestra en el ser (das Wesende des Seins), encontrar una sola palabra, la palabra única ${ }^{20}$.

La referencia a la unicidad hace decir a Derrida que, a pesar de los enormes esfuerzos en juego, la posición de Heidegger alienta una suerte de «esperanza» ilegítima, contracara de la nostalgia, de encontrar una palabra propia y un nombre único para el ser. Si se lleva adelante el ejercicio derridiano de pensar a partir de la noción de «huella de huella», que hunde todo origen en el terreno de lo inasible, se advertiría en Heidegger una ruptura incompleta con los

19 J. Derrida, Dar el tiempo, op. cit., cap. 2, nota 8.

20 J. Derrida, «La différance», conferencia pronunciada en la Sociedad Francesa de Filosofía, el 27 de enero de 1968, publicada simultáneamente en el Bulletin de la Societé française de philosophie (julio-septiembre, 1968) y en Theorie d'ensenble (col. Quel, Ed. de Seuil, 1968); en J. Derrida, Márgenes de la filosofía, trad. Carmen González Marín (Madrid: Cátedra, 1998), 27. 
fundacionismos. Esta crítica derridiana se ubica en la línea de objeciones según las cuales Heidegger no solo debe producir la Kehre por la recaída en la lógica del sujeto moderno que se encuentra en el tratamiento del ser para la muerte, sino que incluso el proyecto del pensar meditativo asociado con el Ereignis supone una cierta reincidencia: si el acontecimiento resulta pensable es que se ha rendido a la lógica del fundamento. Finalmente se sospecha que esa fuente de «emanación última» se parece demasiado a sus figuras antecesoras de la ontoteología.

Como hemos visto, la imposibilidad del don sirve como elemento para poner en cuestión una dimensión de fundamento que sería inescindible de la actividad de pensar y su lógica comprometida con la dinámica sujeto-objeto. Las referencias heideggerianas al pensar meditativo, el salto y el pensar tautológico serían, en este sentido, insuficientes para quebrar el modelo subyacente. Elocuente en este sentido resulta la afirmación de Derrida en su diálogo con Marion en la «Charla de Villanova», cuando a propósito del don sostiene:

Yo nunca dije que no hay don. No. Dije exactamente lo contrario. ¿̇Cuáles son las condiciones para que digamos que hay don, si no podemos determinarlas teóricamente, fenomenológicamente? Es a través de la experiencia de la imposibilidad, de que su posibilidad es posible como imposible ${ }^{21}$.

De esta afirmación se infiere que la imposibilidad del don apunta a la matriz de pensamiento desde la cual se puede tematizar esta cuestión. Se ha visto que el enfoque antropológico y su apelación al intercambio económico son inservibles, pero también resulta deficiente el marco fenomenológico, que llamativamente resulta aquí puesto en ecuación con la categoría de «teórico» ${ }^{22}$. Según esta perspectiva, el pensar fenomenológico en las derivas que pretenden ampliar sus límites con la reducción existencial y la reducción a la donación pretenden conferir potencia a la práctica filosófica, cuando estrictamente resultan impotentes para dar cuenta cabal de las metas que se

22 Dirá en esta línea Derrida que «un evento como tal, así como el don, no puede ser conocido como un evento, como un evento presente». Ibíd., 60. 
proponen y se pierden en facetas de nostalgias del origen, en lugar de enfrentar la diseminación del sentido y la estructura de «huella de huella» que debería asumirse en lugar de buscar sucedáneos. El don es imposible en términos teóricos/fenomenológicos, porque esta esfera solo entrevé de lejos la dimensión de lo indecidible.

\section{Triple epoché y donación}

Con una actitud escéptica respecto de la solución derridiana, Marion avanza en la propuesta de reducción del don a la donación, que resulta un dispositivo adicional a las reducciones propuestas por Husserl y Heidegger. Sobre esta base y con el propósito de reivindicar el planteo del don, Marion sugiere que se debe rechazar el apotegma inicial de Derrida, según el cual las condiciones de posibilidad del don son las condiciones de imposibilidad del don, señalando que esta coextensión es un indicio de que la efectivas condiciones de posibilidad deben buscarse fuera de la lógica del intercambio, es decir por fuera de la actitud natural ${ }^{23}$.

De acuerdo con Marion, el proceso impugnatorio respecto de Mauss deja preso a Derrida en el dispositivo standard donador-dondonatario que esconde el esquema causal aristotélico (donador-causa eficiente; don-causa formal y material; donatario-causa final) apto para el análisis de «fenómenos pobres» o entes comunes del mundo, con lo cual se elimina el hecho del don. Si la economía «economiza», disuelve, contrae, la donación, esta debe ser recuperada con la triple epoché que pone entre paréntesis donatario, don y donador ${ }^{24}$. A continuación relevaremos las figuras utilizadas por Marion.

\footnotetext{
23 «El don ya no podrá considerarse nunca más en el sistema de intercambio, cuya reciprocidad liga donador y donatario, y se inmoviliza en la presencia: en esta pretendida economía del don, se está economizando literalmente la donación, transformando totalmente su don en un ente subsistente, presente en permanencia, dotado de valor (...) y de finalidad (...), transformándolo en un ente corriente.» J. L. Marion, Siendo dado. Ensayo para una fenomenología de la donación (Madrid: Síntesis, 2008), 153.

Ibíd., 156.
} 
La primera epoché es aquella que reduce al donatario y muestra la posibilidad de un don sin este. Marion se apresura a afirmar que no solo la donación se realiza tras la puesta entre paréntesis del donatario, sino que, por el contrario, si el donatario estuviera siempre presente la donación «desaparecería pura y simplemente». Si el donatario precediera al don -esperándolo o reclamándolo-y subsistiera tras él -disfrutándolo u apropiándose del mismo--, el don sufriría una «doble descalificación». Por un lado, el donatario podría considerar que no solo es un actor en la relación sino la causa eficiente por «haberlo producido mediante súplicas», o bien la causa final por haberlo «merecido justamente» por sus obras o por su miseria. En ambos casos el don se «reduciría a un simple efecto», habilitando así un «dispositivo metafísico corriente». Por otra parte, el caso de que el donatario permanezca presente tras la donación habilitaría la posibilidad de la destrucción del don, ya que aunque el mismo haya sido en un principio gratuito sería imposible no devolverlo. Marion lo ejemplifica con la figura del anónimo que se patentiza, por ejemplo, en las campañas de recolección de fondos ${ }^{25}$. El donador da sin conocer a «quién» da, aunque el rostro que se presenta resulte conocido - p. e. el actor que presta su rostro para una campaña-. Sin embargo, aclara Marion, es posible que el donatario permanezca presente y la devolución del don latente. Por este motivo, surge la figura del enemigo, es decir, aquel que por definición no devuelve ni acepta nada. En este caso «el donatario se encuentra absolutamente reducido». El enemigo es aquel que permite amar gratuitamente «a pura pérdida» lo que significaría «dar en vano, por nada, sin razón» ${ }^{26}$. En este estadio surge la figura del ingrato, es decir aquel que por el peso del don decide rechazarlo para «no deber nada a nadie» y patentiza que aun en el caso del don rechazado no se anula la donación ${ }^{27}$. Por último, surge la figura de lo universal, donde el donador actuaría -fenomenológicamente y no según la actitud natural- como donatario: es él a quien el don se da 
y aparece. Con el objetivo de ejemplificarlo, Marion recurre a las figuras del «don de sí» por la nación, por la humanidad o bien, por los hombres futuros ${ }^{28}$. Así, incluso sin donatario, el don se cumple, ya que basta que se dé para que se muestre.

La segunda epoché es aquella que pone entre paréntesis al donador. Ante el cuestionamiento sobre la posibilidad de pensar un don sin donador, Marion afirmará que no solo esta puesta entre paréntesis no riñe con la posibilidad sino que sin la misma la donación se vería comprometida, ya que el donador se encontraría «visible, disponible y permanente» y ello conllevaría la desaparición del don. En este sentido surge la figura de la herencia, donde el don aparece justamente porque quien lo da falta ${ }^{29}$. Al heredar se generaría una deuda y una contrapartida pero no con el donador, sino con el Estado que «no me ha dado nada y coge su parte (...) aunque esa parte no les estuviera destinada (según el don)». Aunque lo deseara el donador no respondería mi llamada y por este motivo no podríamos hablar de intercambio. Además de la herencia -o ausencia de donador-Marion pasa revista a la figura de la inconsciencia en donde el donador está presente pero ignorante del efecto de su don. Cuando el donador da sin reservas, a pesar de su proximidad y autoafección, ignora el efecto que está realizando en el donatario. La pasión del Otro sería irreductible a su punto de vista y en este sentido el donador no sería consciente de sí mismo. Para ejemplificar la figura de la inconsciencia Marion recurre al deportista, artista y amante. Respectivamente ignoran el goce que produce en el donatario la victoria, el goce estético y el erótico, respectivamente ${ }^{30}$. Por último Marion examina la figura del endeudamiento -ante la imposibilidad de devolver nada a nadie, el donatario debe reconocerse a sí mismo en deuda de manera definitiva $-^{31}$ y la del reconocimiento ${ }^{32}$. Así, el 
don se cumple incluso sin donador, ya que basta que se muestre para que se dé al donatario ${ }^{33}$.

La tercera epoché, el don sin objeto revela que hay donación incluso ante la falta del ente entregado, sin el cual no habría intercambio. Dice Marion que «el don puede a menudo (...) no tratarse de ningún objeto. (...) cumplir una promesa, una reconciliación, mantener una amistad, (...) una bendición o una maldición ${ }^{34}$ serían ejemplos de ello. Por este motivo concluye que «el don no consiste, pues, en un objeto transferido, sino en su donabilidad $»^{35}$ y en su aceptabilidad ${ }^{36}$.

Este proceso permite a Marion afirmar que luego de ser aprehendido el don bajo el régimen de la reducción es posible concebirlo sin objeto, es decir, distinto del modo en que surge bajo la actitud natural, donde aparecería como un objeto o ente e indefectiblemente sería reconducido al mero intercambio. Por este motivo dirá Marion que no descalifica el intento derridiano por explicitar el don, ya que este se limita a explicitar el intercambio sin discurrir efectivamente sobre el mismo.

\section{Perspectivas de una fenomenología de lo inaparente}

Como hemos visto, las variaciones heideggerianas que desplazan el «lugar» de la reducción y buscan un «más allá del ser» despiertan discusiones en las derivas de la fenomenología francesa en relación con la naturaleza de esta empresa. Las objeciones pueden agruparse en dos orientaciones principales que revelaremos a continuación y tienen que ver, por un lado, con el supuesto giro o conversión teológica, y por tanto ya no filosófica, del enfoque, y, por otro, con la permanencia de mecanismos típicamente fenomenológicos que funcionen como indicios inequívocos de que esta línea está activa en el planteo. 
Revisemos primero lo que refiere al llamado «giro teológico». Este aspecto es intrínsecamente llamativo, ya que el punto de origen aparece en el autor de Fenomenología y teología, texto de 1927 en que Heidegger sostiene:

La fe, como una posibilidad específica de la existencia, es en su núcleo propio el enemigo mortal de la forma de existencia que es una parte fundamental de la filosofía (...). La fe es hasta tal punto absolutamente enemiga mortal ni siquiera comienza a querer en sentido alguno entrar en batalla con ella. (...) No hay tal cosa como una filosofía cristiana; eso es un completo «círculo cuadrado». Por otra parte, tampoco hay tal cosa como una teología neokantiana, axiológica o fenomenológica, como no hay una matemática fenomenológica. Fenomenología es siempre solo el nombre para el proceder de la ontología, un proceder que se distingue esencialmente del de todas las otras ciencias positivas (Phänomenologie ist immer nur die Bezeichnung für das verfahren der Ontologie, das sich wesenhaft von dem aller anderen positiven Wissenschaften unterscheidet) ${ }^{37}$.

Este hiato radical que pone a la teología a una marcada distancia de la fenomenología es un recaudo que para algunos autores queda abandonado en la línea de fenomenología francesa que mencionamos y se arriesga a vulnerar los pilares de este enfoque. Con el propósito de ampliar los ámbitos de influencia pondría en riesgo la diferencia entre la filosofía y las ciencias particulares destruyendo «las cuestiones de dominio y preeminencia» ${ }^{38}$ que deben regir el diálogo entre ellas. Esto es lo que se impugna primariamente en el trabajo pionero de D. Janicaud, que denunció una contaminación de los principios de la fenomenología en tanto se subordinó la descripción de los fenómenos a la esencia de la fenomenalidad.

Janicaud diagnostica un origen de este desvío en una fórmula llamativa en el Seminario de Zähringen de 1973, donde en el marco de un análisis del proemio del poema Parménides y su relación con el fragmento 6 se refiere a lo que llama el pensamiento tautológico y agrega:

M. Heidegger, «Fenomenología y teología», trad. Helena Cortés y Arturo Leyte, en Hitos (Madrid: Alianza, 1927), 53. Cf. la carta del 11 de marzo de 1964, donde se menciona la teología en relación con las condiciones del pensar no objetivante. 
Así comprendida, la fenomenología es un camino que conduce allí, adelante; y deja mostrarse a aquello ante lo cual es conducido. Esta fenomenología es una fenomenología de lo inaparente (Diese Phänomenologie ist eine Phänomenologie des Unscheinbaren) ${ }^{39}$.

De igual modo, el juicio que Heidegger mismo traza respecto de su relación con la herencia husserliana en Mi camino en la fenomenología, de 1963, subraya la continuidad y enfatiza los elementos fenomenológicos de su empresa. Más allá de esta pretensión, Janicaud sostiene que el planteo del último Heidegger «no tiene nada que ver con la empresa husserliana de constitución $»^{40}$, y en este recorrido corre el riesgo de «abandonar los fenómenos», caso en el cual quedarían pocas razones para decir que está en pie el aliento fenomenológico. Este movimiento estaría en la base del «giro teológico» que se desplazaría irremisiblemente hacia la búsqueda de lo originario, no solo por las razones que hemos visto aducidas por Derrida en relación con la búsqueda de un fundamento, sino porque los tratamientos sobre lo sagrado, que están también presentes en el filósofo de Friburgo, convierten el enfoque en teología. En este sentido, afirma Janicaud que «sin la Kehre de Heidegger no habría giro teológico» ${ }^{41}$.

Precisamente, el planteo marioniano resultaría en esta lectura una apuesta más alta en esta línea a través de la adición de una tercera reducción: si Husserl planteó la reducción al objeto y Heidegger advirtió una reducción existencial del ente al ser, Marion completó este movimiento con una reducción a la donación. Este sostiene que se trata de una operación en total concordancia con la orientación husserliana, ya que en este ámbito habría una preponderancia de la donación sobre la intuición ${ }^{42}$, dado que esta última depende de una significación previa. De este modo, la objetividad es derivada respecto de un yo al cual no le cabe el ser, por lo cual dirá que «el yo, y la

39 M. Heidegger, «Seminario de Zahringen, 1973», trad. O. Lorca, A Parte Rei 37 (2005), consultada en marzo 16, 2011, http://serbal.pntic.mec.es/ cmunoz11/lorca37.pdf, \# 487.

40 D. Janicaud, Phenomenology and the «theological turn»: the French debate (New York: Fordham University Press, 2000), 30.

41 Ibíd., 31.

42 J. L. Marion, Réduction et donation: recherches sur Husserl, Heidegger et la phenomenologie (Paris: PUF, 1989), 28 ss. 
reducción fenomenológica con él, no es» ${ }^{43}$. Esto nos pone en camino de evitar la limitación de toda la tarea de la fenomenología al plano de la objetividad y proyecta la posibilidad de una fenomenalidad que no se defina en términos de presencia. Janicaud interpreta esta posición como un signo de debilitamiento hacia una «fenomenología cada vez más negativa ${ }^{44}$.

La objeción central que se presenta desde esta perspectiva es que la impronta teológica marca todo el enfoque, ya que al tematizar los fenómenos saturados, específicamente el de revelación, Marion debe dar ejemplos que se convierten en casos de Revelación, como nota Holzer indicando con la inicial mayúscula la asignación de aspectos asociados con lo sagrado y por tanto pertenecientes al ámbito de la teología ${ }^{45}$. La observación fenomenológica resultaría incompatible con la dimensión fideísta ínsita en la revelación. Podría decirse que lo que se pone en cuestión es el ámbito hermenéutico operante en toda captación fenomenológica, que en Derrida es determinante y en Marion queda debilitado para poner, en primer plano, la dimensión de la donación de fenómenos, en el desafío de analizar casos en que no hay objeto ni presencia.

Marion se defiende sosteniendo que no hay en su planteo negatividad sino un nivel de abstracción que testimonia su calidad filosófica ${ }^{46}$, y niega de manera taxativa que la naturaleza teológica esté implicada de manera determinante, ya que la donación constituye un tema fenomenológico propio, de modo que la asociación con la teología resultaría una estrategia de descalificación ${ }^{47}$. A pesar de estas pretensiones de Marion, esta distinción no ha recibido una aprobación general, como surge de las objeciones de R. Horner, para quien su propuesta, si bien no se trataría de una actualidad de la

43 Ibíd., 240.

44 D. Janicaud, op. cit., 65.

45 V. Holzer, «Autour du prof. J. L. Marion: Phénoménologie radicale et phénomène de révélation», Transversalités: revue de l'Institut Catholique de Paris 70 (1999): 66-68.

46 J. L. Marion, Siendo dado. Ensayo para una fenomenología de la donación, op. cit., 136.

47 Ibíd., 137. 
teología, apunta a habilitar su posibilidad ${ }^{48}$, y en ese plano surgen los inconvenientes asociados con el tipo de actitud fenomenológica implicada en los fenómenos saturados. Para Horner, a pesar de que Marion parece sugerir que es posible mantener una observación desapasionada y puramente teórica, se objeta que no se puede permanecer en actitud fenomenológica y por tanto neutral frente a un fenómeno de revelación/Revelación, por lo cual existe una tensión irresoluble entre teología y fenomenología ${ }^{49}$. Así, al avanzar hacia ejemplos o al detenerse en la actitud ante fenómenos saturados se vulneran condicionamientos fenomenológicos y se ingresa en el terreno de la teología.

Esta objeción se conecta con la que dirigió J. Milbank a la lógica marioniana de la donación, cuando señala hacia el reconocimiento de la otredad, donde el exceso es tal, porque precede al yo que inevitablemente reconoce la llamada hacia sí. Este tratamiento, asociado con el análisis del ícono, nos resulta de especial interés porque sugiere que, contra lo que sostienen Derrida y Marion, la donación está efectivamente caracterizada por el intercambio, ya que la donación divina sucede inexorablemente y el receptor no puede rechazarla, de modo que su naturaleza misma reside en la afectación del receptor de lo dado como don ${ }^{50}$. Desde esta matriz, afirma Milbank, no es del todo cierto que la lógica del intercambio sea ajena a la lógica del don, y más aun, esta se da en superficie precisamente en el fenómeno de revelación, de modo que las pretensiones aneconómicas del enfoque marioniano se ven comprometidas no solo por el riesgo de reaparición de los mecanismos de la objeción derridiana, sino más radicalmente porque este argumento sugiere que mantener distantes fenomenología y teología en este punto se vuelve difícil, ya que por definición hay una afectación que impide una actitud neutral y propicia el predominio de la dimensión de la fe o la creencia.

\footnotetext{
48 R. Horner, op. cit., 157.

49 Ibíd., 158.

50 J. Milbank, «Can a Gift be Given? Prolegomena to a Future Trinitarian Metaphysic», en L. G. Jones and S. E. Fowl, eds., Rethinking Metaphysics (Oxford: Blackwell, 1995), 135.
} 
Cabe notar que en estos enfoques se conjugan posiciones descalificadoras, como la de Janicaud, que ven un demérito en el hecho de apartarse de la fenomenología, con otras que ancladas en una perspectiva religiosa contemplan con agrado la idea de que el planteo marioniano pertenezca de lleno a la teología y aducen argumentos que van contra el autor mismo saludando el naufragio de su voluntad de hacer primar los rasgos fenomenológicos. En esta línea se ubican posiciones como la de Holzer, Horner o Milbank.

Si pasamos al segundo grupo de objeciones, nos encontramos nuevamente con la voz de Derrida, que señala que la relación entre donación y don es problemática y echa dudas sobre la supuesta continuidad del planteo marioniano con los de Husserl y Heidegger. Para Derrida la fenomenología está inevitablemente unida a la presencia y se vuelve inoperante si esta falta, mientras que Marion sostiene su posición en la no identidad entre presencia e intuición, punto que le permite asociar donación con presencia. Esto nos devuelve al problema de la posibilidad misma del don, que se revela unido al problema de la identidad y límites de la fenomenología. La «Charla de Villanova» es especialmente clara a este respecto, porque muestra la especificidad de estas críticas respecto del primer grupo. Esto se advierte en el entramado mismo del diálogo, propiciado por huéspedes preocupados por el tópico del don en terreno teológico, que se ven contrariados porque tanto Marion como Derrida se muestran más preocupados por discutir si el don es susceptible de un análisis fenomenológico que por sus conexiones teológicas. No solo Marion comienza diciendo que no está interesado en esta temática ${ }^{51}$, sino que Derrida comparte la perspectiva, hasta el punto de que, cuando luego de repetidos intentos frustrados por instalar el tema religioso el moderador encuentra un vínculo religioso ${ }^{52}$, Derrida insiste con una

51 «Bien, voy a defraudarte diciendo que ahora, en este estado de mi trabajo, tengo que enfatizar que no me interesa el don y no me interesa el sentido religioso del don». J. Caputo, op. cit., 56.

52 «Jean-Luc finalmente toca la conexión entre la fenomenología del don y la palabra revelada. Aprecio que se llegue a estas cosas tangencialmente, de manera oblicua y de a poco, pero dados los límites de tiempo y dado que esto no es, estrictamente hablando, un seminario sobre fenomenología o sobre la donación sino una conferencia sobre religión y posmodernidad, ¿̇iensas, Jacques, que es posible avanzar en una fenomenología de la donación religiosa?». Ibíd., 64. 
vuelta atrás a la perspectiva fenomenológica ${ }^{53}$, que hace declarar con desazón al moderador un «yo abandono» ${ }^{54}$, y agregar poco después:

¡Es más fácil juntar a unionistas y nacionalistas en Ulster para hablar de la paz que lograr que ustedes dos hablen de Dios $!^{55}$.

Lo que se abandona es el intento de resolver el diálogo dando por sentado un "giro teológico» y la dificultad que frustra al moderador no es otra que la independencia del problema del don respecto del eje teológico. La persistencia de este diálogo a contramano responde precisamente a la dimensión propiamente filosófica del planteo, que versa sobre los límites de la fenomenología y la inclusión o no de los planteos de Derrida y Marion en esta línea. Nótese que el desacuerdo es doble, ya que no sólo Derrida supone que Marion no hace fenomenología, sino que Marion sostiene que Derrida, a pesar de sus reparos, nunca salió de los límites de este enfoque. Llamativamente afirma Marion:

Sostengo que todavía confío en la fenomenología y adivino que estás más dentro del campo de la fenomenología de lo que admites. Pero esto será un tema, si es que lo es, para nuestros sucesores ${ }^{56}$.

Esta tarea se impone, efectivamente, en la discusión actual no tanto por el hecho de decidir quién está dentro y quién fuera del enfoque, sino más bien para aclarar cómo está conformado el espacio teórico de la disciplina en nuestro tiempo. Si volvemos a los puntos centrales de la discusión, puestos en este diálogo en primer plano, se parte, evidentemente, de la pretensión marioniana de encarnar la apertura de los grandes temas de la fenomenología que ya estaban presentes en Husserl y Heidegger, de modo que podría ser definida como «ciencia de lo dado» ${ }^{57}$.

53 «Pero al preguntarme eso está usted recontextualizando y autorizándome a volver a atrás, no a comenzar de la última oración». Ídem.

54 Ídem.

$55 \quad$ Ibíd., 68.

56 Ídem.

57 Ibíd., 56 
Frente a esto, la objeción principal reside en la interposición del marco derridiano que sugiere una total heterogeneidad entre la lógica del don y el enfoque fenomenológico, lo cual lo convierte, como hemos visto, en imposible, irreductible a toda matriz para dar cuenta de objetos, de modo que, dice Derrida:

El don es totalmente ajeno al horizonte de la economía, ontología, conocimiento, enunciados constatativos, determinación teorética y juicio (The gift is totally foreign to the horizon of economy, ontology, knowledge, constantive statements and theoretical determination and judgement ${ }^{58}$.

Se trata, entonces, de justificar la posibilidad de describir el don, condición para mostrar la plausibilidad de esta apuesta de ampliación de la fenomenología a lo inaparente. La prueba más básica que aduce Marion está asociada a la mostración de casos de don sin la estructura completa donador-don-donatario. La importancia de este análisis, al que nos hemos referido en el punto 3, radica en mostrar que el don se rige por reglas totalmente diferentes de las que corresponden a los entes y remiten a la donación, que resulta, de este modo, una estructura inmanente de cualquier tipo de fenomenalidad. En última instancia, lo que se pone en juego es la posibilidad de instalar un ámbito en que las coordenadas de pensamiento aplicables a los entes, con la causalidad en primer término, se pongan entre paréntesis para describir fenómenos como dados sin preguntarse por el donador. En este sentido, los ejemplos de don sin donador son un indicio de la exigencia de habilitar formas de dar cuenta de este tipo de casos. En la perspectiva de Marion es allí donde se encuentra la más genuina experiencia del fenómeno, lo cual lo hace sostener

Pienso que la dificultad de la fenomenología es ahora volverse más amigable hacia algunos fenómenos que no pueden ser descriptos como objetos o entes. (...) Así, mi hipótesis como fenomenólogo es que no deberíamos tratar de constituirlos, sino aceptarlos en sentido de aceptarlos 
como dados y eso es todo (we should not try to constitute them, but accept them-in any sense of accepto- as given and that is all $)^{59}$.

Es preciso enfatizar los esfuerzos de Marion por resaltar la vigencia del programa husserliano a través de la apelación a la noción de «filosofía primera». La reducción a la donación oficia de estrategia para desplazarse hacia un dispositivo que permita dar cuenta de todo fenómeno, incluyendo sus variantes saturadas. Una revisión de la estructura de Acerca de la donación, obra en la que Marion sintetiza buena parte de sus tesis generales, explicita la intención de colocar la fenomenología en un plano último. La pregunta en este caso es si el espacio definido con estas cuestiones no destruye las pretensiones de la filosofía comprometiéndose con actitudes más cerca de la actitud natural de lo que pueden dictar los límites fenomenológicos.

Nuestro recorrido sirve para sostener que no hay una respuesta taxativa a esta cuestión sin tomar partido primero por el problema de los límites disciplinares que siempre han sido altamente inestables. En efecto, esta serie de elementos deben ser tenidos en cuenta en un examen del cual este trabajo pretende ser una guía programática de cuestiones abiertas, a la manera de un punto de partida. Probablemente tenga razón Marion en que el problema de los límites del campo de la fenomenología está en manos de los sucesores o receptores de estas propuestas filosóficas y será entonces por los mecanismos de instauración del discurso porvenir en el área que emergerán los criterios que decidan en uno y otro sentido. La perspectiva hasta ahora sugiere que la proliferación de corrientes que exploran las figuras de la excedencia, entre las que hay que sumar a la propuesta de Marion otras como las de Henry y Rombach, indican que antes que un desvío esta dirección resulta un cauce abierto tempranamente en la disciplina y un llamado a profundizarse más que a agotarse. 


\section{Bibliografía}

Berciano, M. «Ereignis. La clave del pensamiento de Heidegger». Themata 28 (2002): 47-69.

Caputo, J. God, the Gift, and Postmodernism. Indianapolis: Indiana University Press, 1999.

Derrida, J. Dar el tiempo. Traducido por Cristina de Peretti. Buenos Aires: Paidós, 1991.

. «La différance». Conferencia pronunciada en la Sociedad Francesa de Filosofía, el 27 de enero de 1968, publicada simultáneamente en el Bulletin de la Societé française de philosophie (julio-septiembre, 1968) y en Theorie d'ensenble (col. Quel, Ed. de Seuil, 1968); en Derrida, J. Márgenes de la filosofía, traducido por Carmen González Marín. Madrid: Cátedra, 1998.

. Posiciones. Traducido por M. Arranz. Valencia: Pre-Textos, 1977.

Heidegger, M. Ser y tiempo. Traducido por José Gaos. Buenos Aires: Fondo de Cultura Económica, 1927.

. «Fenomenología y teología», Traducido por Helena Cortés y Arturo Leyte, 66-73. En Hitos. Madrid: Alianza, 1927.

- Los Problemas básicos de fenomenología, Traducido por Alberto Allard, tomada de la transcripción inglesa de Albert Hofstader, The Basic Problems of Phenomenology. Studies in Phenomenology and Existential Philosophy, Indiana: Indiana University Press, 1927.

. Carta sobre el humanismo. Traducido por Helena Cortés y Arturo Leyte. Madrid: Alianza Editorial, 2000.

. «El principio de identidad». En Identidad y diferencia, traducido por Helena Cortés y Arturo Leyte. Barcelona: Anthropos, 1990. 
Heidegger, M. «Tiempo y ser», Traducido por M. Garrido y Félix Duque. En Tiempo y ser. Madrid: Tecnos, 2000. . «Mi camino en la fenomenología». Traducido por Félix Duque. En M. Heidegger. Tiempo y ser. Madrid: Tecnos, 2000. . «Seminario de Zahringen, 1973». Traducido por O. Lorca. A Parte Rei 37 (2005). Consultada en marzo 15, 2011. http:// serbal.pntic.mec.es/ cmunoz11/lorca37.pdf.

Holzer, V. «Autour du prof. J. L. Marion: Phénoménologie radicale et phénomène de révélation». Transversalités: revue de l'Institut Catholique de Paris 70 (1999).

Horner, R. Rethinking God as Gift. Marion, Derrida and the Limits of Phenomenology. New York: Fordham University Press, 2001.

Horner, R. Jean-Luc Marion: A Theo-logical Introduction. Aldershot: Ashgate Publisher, 2005.

Husserl, E. Ideas Pertaining to a Pure Phenomenology and to a Phenomenological Philosophy, trad. R. Rojcewicz. New York: Springer. 1990.

. Meditaciones cartesianas. Traducido por José Gaos y M. García Baró. México: Fondo de Cultura Económica, 1985. . La crisis de las ciencias europeas y la fenomenología trascendental. Traducción española y nota editorial de Jacobo Muñoz y Salvador Mas. Barcelona: Crítica, 1991.

Janicaud, D. Phenomenology and the "theological turn»: the French debate. New York: Fordham University Press, 2000.

Lawlord, L. Derrida and Husserl. The basic problem of phenomenology. Indianapolis: Indiana University Press, 2002.

Mackinlay, S. Interpreting excess. Jean-Luc Marion, Saturated Phenomena, and Hermeneutics. New York: Fordham University Press, 2010. 
Marion, J.L. Réduction et donation: recherches sur Husserl, Heidegger et la phenomenologie. Paris: PUF, 1989. . Siendo dado. Ensayo para una fenomenología de la donación. Madrid: Editorial Síntesis, 2008.

. Acerca de la donación. Una perspectiva fenomenológica. Buenos Aires: UNSAM-Baudino, 2005.

Milbank, J. «Can a Gift be Given? Prolegomena to a Future Trinitarian Metaphysic». En L.G. Jones and S.E. Fowl, eds., 119-161. Rethinking Metaphysics. Oxford: Blackwell, 1995.

Restrepo, C. «El "giro teológico" de la fenomenología: Introducción al debate». Pensamiento y Cultura 13, Vol, 2 (2010): 115-126.

Walton, R. «Reducción fenomenológica y figuras de la excedencia». Tópicos 16 (2008): 169-187.

Recibido: 19 de abril de 2012 Aceptado: 25 de octubre de 2012. 